\title{
Lack of association between adult asthma and the tumour necrosis factor $\alpha-308$ polymorphism gene
}

\author{
R. Louis*, E. Leyder*, M. Malaise ${ }^{\#}$, P. Bartsch*, E. Louis
}

\begin{abstract}
Lack of association between adult asthma and the tumour necrosis factor $\alpha-308$ polymorphism gene. R. Louis, E. Leyder, M. Malaise, P. Bartsch, E. Louis. C)ERS Journals Ltd 2000

ABSTRACT: Tumour necrosis factor (TNF) $\alpha$ is a cytokine endowed with potent inflammatory properties that may contribute to airway inflammation in asthma. It has previously been shown that the single base pair polymorphism-308 (G to $A$ substitution) in the promoter of $\mathrm{TNF} \alpha$ gene results in enhanced cytokine secretion. Whether this polymorphism is associated with the presence of phenotypic expression of asthma is questioned.

In this study the relative frequency of TNF1 and TNF2 alleles in a population of adult healthy subjects $(n=98)$ and adult Caucasian asthmatics $(n=95)$ was compared taking into account their disease severity, atopic status and their smoking habit.

For the whole group of asthma the genotype frequency for $1 / 1,1 / 2,2 / 2$ were $67 \%$, $33 \%$ and $0 \%$, respectively, and not significantly different from those found in the control group that reached $70 \%, 28 \%$ and $2 \%$ respectively $(p>0.05)$. The allele frequencies in asthma were $86 \%$ and $14 \%$ for TNF1 and TNF2 respectively while the corresponding figures were $85 \%$ and $15 \%$ in the control group $(p>0.05)$. Furthermore, subdividing asthmatics into severe forced expiratory volume in one second $<60 \%$ pred), atopic or smoking patients did not show any significant association with this TNFa polymorphism.

To conclude the polymorphism $\mathbf{- 3 0 8}$ in the promoter of the TNF $\alpha$ gene does not confer a susceptibility to develop asthma nor to grade its severity.
\end{abstract} Eur Respir J 2000; 16: 604-608.

\author{
*Dept of Pneumology, and "Inflammatory \\ Disease Research Group, CHU Sart- \\ Tilman, University of Liege, Belgium. \\ Correspondence: R. Louis \\ Dept of Pneumology \\ CHU Sart-Tilman \\ 4000 Liège \\ Belgium \\ Fax: 3243668846 \\ Keywords: Asthma \\ genetics \\ phenotypes \\ polymorphim \\ tumour necrosis factor- $\alpha$
}

Received: January 182000

Accepted after revision June 62000
Even if the role of environment is critical in the clinical expression of asthma, epidemiological studies have firmly established a genetic component in this disease. However, the genes involved in asthma are still unknown and are likely to be numerous. One way to unravel the potentially important genes in polygenic disorders such as asthma is to perform association studies with candidate genes [1-3].

Over the past $15 \mathrm{yrs}$ the airways inflammatory component of asthma has been clearly demonstrated and accumulating evidence suggests that the immune disorder leading to airways inflammation is partly controlled by the genetic background of the patient [4]. Tumour necrosis factor (TNF) $\alpha$ is a potent proinflammatory cytokine the altered secretion of which could contribute to the inflammatory process in asthmatic airways [5]. A functional polymorphism for TNF $\alpha$ has been recently described. It is characterized by a single base pair (SBP) polymorphism at position -308 in the promoter of TNF $\alpha$ [6]. The mutation leading to the allele 2 has been shown to be associated with an enhanced transcription of TNF $\alpha$ [7] as well as increased release of TNF $\alpha$ from blood mononuclear cells [8] or whole blood [9] in response to endotoxin.

The first two studies looking at this polymorphism in a population of atopic asthma yielded contradictory results $[10,11]$. One of these used a validated and standard questionnaire to define asthma in nuclear families [10] while the other one, which exclusively targeted childhood asthma, included the notion of histamine bronchial hyperresponsiveness in the asthma definition [11].

In this study the frequency of TNF $\alpha-308$ polymorphism in a population of adult asthmatics seen in an outpatient clinic at the University hospital has been assessed. In order to increase the specificity of the diagnosis, asthma was not only defined by the clinical history but also by the demonstration of a significant reversibility of airway obstruction after either inhaled bronchodilator or a short course of oral corticoids, or a significant methacholine bronchial hyperresponsiveness in case of normal baseline bronchial calibre. In order to assess any potential association between TNF $\alpha$ polymorphism and different asthma phenotypes, the patients were further characterized with respect to their atopic status, their smoking history and their disease severity as judged by the extent of lung function impairment.

\section{Materials and methods}

\section{Subjects}

One-hundred unrelated Caucasian asthmatics, whose characteristics are given in table 1 , were consecutively recruited for blood sampling by the same physician from the outpatient clinic of Liège University Hospital between 
Table 1. - Subject characteristics

\begin{tabular}{lcc}
\hline & $\begin{array}{c}\text { Control } \\
\text { population }\end{array}$ & Asthmatics \\
\hline Subjects n & 98 & 95 \\
Age yrs & $36(19-58)$ & $41(17-74)$ \\
Sex ratio M/F & $45 / 53$ & $38 / 47$ \\
FEV1 \% pred & $103(68-132)$ & $81(25-127)$ \\
FEV1 <60\% pred & 0 & $18(19)$ \\
Smoking history & $24 / 98(24)$ & $46 / 95(49)$ \\
Smokers $>5$ pack yrs & $20 / 98(20)$ & $39 / 95(41)$ \\
Atopy & $11 / 98(11)$ & $68 / 95(72)$ \\
Total serum IgE kU.L $\mathrm{L}^{-1}$ & ND & $63(<3.5-6280)$ \\
\hline
\end{tabular}

Data expressed as a mean (range) or as frequency, (\%) total serum immunoglobulin (Ig)E is expressed as geometric mean (range). M: male; F: female; FEV1: forced expiratory volume in one second; ND: not detected.

April 1996 and April 1997. Asthma was diagnosed as a clinical history of recurrent episodes of breathlessness, cough and/or wheeze associated either with methacholine bronchial hyperresponsiveness, when baseline FEV1 was $\geq 70 \%$ pred and/or with a reversibility of bronchial obstruction when baseline FEV1 was $<80 \%$ predicted. Methacholine bronchial challenge was carried out by using a jet nebulizer the characteristics of which have been described previously [12]. The subjects inhaled by tidal breathing for $2 \mathrm{~min}$ four-fold increasing concentrations of methacholine starting with $0.06 \mathrm{mg} \cdot \mathrm{mL}^{-1}$ and going up to $16 \mathrm{mg} \cdot \mathrm{mL}^{-1}$ when necessary. FEV1 was measured $60 \mathrm{~s}$ after each inhaled concentration and the challenge stopped when FEV1 fell by $>20 \%$ from baseline. The provocative concentration of methacholine causing a fall in FEV1 of $20 \%$ from baseline (PC20 M) was read off from linear interpolation between the last two points of the curve. Bronchial hyperresponsiveness was defined as a PC20 methacholine $\leq 16 \mathrm{mg} \cdot \mathrm{mL}^{-1}$. Reversibility of airway obstruction was considered significant when FEV1 increased by $>15 \%$ from baseline (and $>200$ $\mathrm{mL}) 15 \mathrm{~min}$ after inhalation of $400 \mu \mathrm{g}$ salbutamol or after a 9-day treatment with oral methylprednisolone (32 $\mathrm{mg}$ for 3 days, $16 \mathrm{mg}$ for 3 days and $8 \mathrm{mg}$ for 3 days). Sixty-nine asthmatics were diagnosed on the basis of methacholine bronchial hyperresponsiveness, 13 on the basis of a reversibility to inhaled $\beta_{2}$-agonists and 13 on the basis of a reversibility after a short course of oral steroids. Clinical data were obtained by review of case records. Eighteen asthmatics were considered to be severe on the basis of two FEV1 values of $<60 \%$ pred despite regular use of inhaled corticosteroids over the last 5 yrs. Atopy was defined as a positive skin prick test (wheal diameter $\geq 3 \mathrm{~mm}$ when compared to the negative control) to at least one of the following common aeroallergens: house dust mites, grass, tree and weed pollens, cat and dog dander, moulds and feathers. Serum immunoglobulin (Ig)E levels were determined by a fluorometric enzyme immunoassay (FEIA; UniCAP System Pharmacia, Uppsala, Sweden).

One-hundred unrelated European Caucasian individuals served as controls. These control subjects were either hospital workers or prospective blood donors. None had a personal history of asthma. This was based on a systematic oral questionnaire, where the subjects were asked to answer the two questions that follow. 1) Have you ever been told by your doctor that you have asthma? 2) Have you ever had recurrent episodes of breathlessness associated with a wheezing occurring particularly during the night, after an exercise or during the pollen season. The subjects were only accepted into the control group if the answers to these two questions were "no".

Approval for this study was given by the Liège Ethical Committee, and the patients gave their informed consent.

\section{Deoxyribonucleic acid extraction}

Genomic deoxyribonucleic acid (DNA) was extracted from $10 \mathrm{~mL}$ of venous blood, using a modified salting out technique [13] and resuspended in sterile distilled water at a final concentration of $0.1-1.0 \mu \mathrm{g} \cdot \mu \mathrm{L}^{-1}$, before use.

\section{Tumour necrosis factor-308 single base pair substi-} tution

As described by VeRJANS et al. [14], a polymerase chain reaction (pcr) involving primers specific for each allele of the $\mathrm{G}$ to $\mathrm{A}$ polymorphism at residue -308 was used. Four primers were used: the $3^{\prime}$ primer $(\mathrm{Cl}$, position: $-144 /-164$ : $5^{\prime}$-TCTCGGTTTCTTCTCCATCG-3') was used in combination with either the $5^{\prime}$ primer $\mathrm{C} 2$ (position -328/ -308G: 5'ATAGGTTTTGAGGGGCATGG-3'), complementary to the TNF1 allele (TNF1), or the $5^{\prime}$ primer C3 (position-328/-308A: 5'-ATAGGTTTTGAGGGGCATGA-3') complementary to the TNF2 allele (TNF2). For each DNA sample, two parallel reactions were performed. The primer pair $\mathrm{C} 1 / \mathrm{C} 2$ were used to produce specific amplification of TNF $1 ; \mathrm{C} 1 / \mathrm{C} 3$ were used to amplify the TNF2 allele. As an internal control, primer D (position -675 to -655 : 5'GAGTCTCCGGGTCAGAATGA-3') was added to each reaction. Amplification was carried out using the cycling conditions previously described [13]. Success of genotyping was $96 \%$. Genotyping was unsuccessful in five samples of asthmatics and two samples of control subjects. Failures were due to either inadequate DNA or nonspecific amplification. After amplification, DNA samples were electrophoresed in 1\% agarose gels containing ethidium bromide, and visualized under ultraviolet light.

\section{Statistics}

Genotype and allele frequencies between groups were compared using a $2 \mathrm{X} 2$ contingency table and chi-squared statistics. Corrections for small numbers were made where necessary using Fisher's exact test. The genotype distributions of the TNF $\alpha-308$ polymorphisms for both the control and the asthmatic groups were found to be in Hardy-Weinberg equilibrium.

\section{Results}

Ninety-eight control subjects and 95 asthmatics were successfully genotyped (fig. 1). For the whole group of asthmatics the frequency of genotypes $1 / 1,1 / 2$ and $2 / 2$ was $67 \%, 33 \%$ and $0 \%$, respectively, while the corresponding figures in the control group were not significantly 


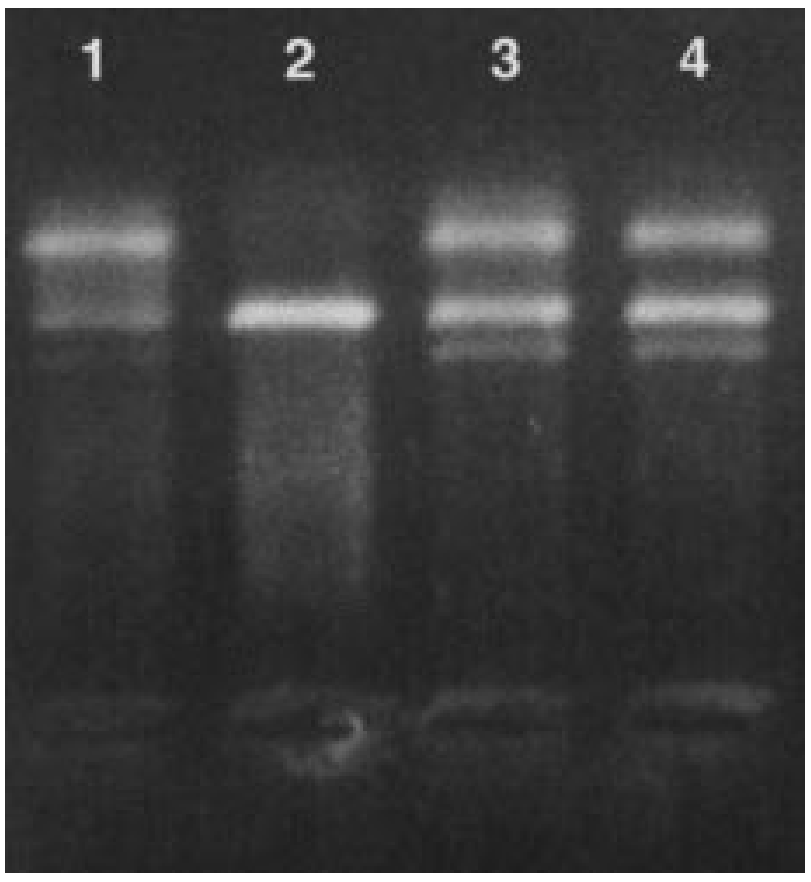

Fig. 1. - Agarose (1\%) gel electrophoresis stained with ethidium bromide showing the two most frequent genotypes $1 / 1$ and $1 / 2$. Lanes 1 and 2 correspond to an homozygous subject for tumour necrosis factor (TNF) 1, while lanes 3 and 4 correspond to a heterozygous subject TNF1/TNF2. Lanes 1 and 3 were obtained with the primers C1, D and $\mathrm{C} 2$ while lanes 2 and 4 were obtained with the primers $\mathrm{C} 1, \mathrm{D}$ and $\mathrm{C} 3$. (See text for details of primers.)

different reaching $70 \%, 28 \%$ and $2 \%$ ( $>>0.05$ ) (table 2 ). In asthma the allele frequencies for TNF 1 and TNF2 were $84 \%$ and $16 \%$, respectively, and not significantly different from those found in control subjects reaching $85 \%$ and $15 \%$, respectively, $(\mathrm{p}>0.05)$ (table 3$)$. Allele frequencies did not differ significantly between asthmatics diagnosed on the basis of a positive methacholine challenge (TNF1/TNF2 frequencies: $86 \% / 14 \%$ ) versus those diagnosed by a significant FEV1 reversibility after $\beta_{2}$-agonists $(85 \% / 15 \%)$ or a short course of oral corticoids $(77 \% / 23 \%)(\mathrm{p}>0.05)$.

Among the asthmatics 28 out of 95 subjects (29\%) reported asthma during the childhood $(<15$ yrs) but there was no difference in the frequencies of TNF1 and TNF2 alleles between those who had childhood onset compared to those who had adult onset of the disease ( $p>0.05$ ). Among the latter 20 out of $67(30 \%)$ had their first symptoms of asthma after the age of 50, but their TNF $\alpha-$ 308 genotype was not different from that found in those in whom the disease started in the middle age (table 4).

Eighteen asthmatics (19\%) had a more severe disease as judged by FEV1 values measured twice $<60 \%$ pred within

Table 2. - Genotype frequency for tumour necrosis factor (TNF) $\alpha-308$ polymorphism (alleles TNF1 and TNF2) in asthma versus control subjects

\begin{tabular}{lccc}
\hline & $1 / 1$ & $1 / 2$ & $2 / 2$ \\
\hline Control population (n=98) & $69 / 98(70)$ & $27 / 98(28)$ & $2 / 98(2)$ \\
Asthma (n=95) & $64 / 95(67)$ & $31 / 95(33)$ & $0 / 95(0)$ \\
\hline
\end{tabular}

Data presented as frequency $(\%)$.
Table 3. - Allele frequency for tumour necrosis factor (TNF) $\alpha-308$ polymorphism (alleles TNF1 and TNF2) in asthma versus control subjects

\begin{tabular}{lcc}
\hline & TNF1 & TNF2 \\
\hline Control population (n=98) & $167 / 196(85)$ & $31 / 196(15)$ \\
Asthma (n=95) & $159 / 190(84)$ & $31 / 190(16)$ \\
\hline
\end{tabular}

Data presented as frequency $(\%)$.

the last 5 yrs despite regular use of inhaled corticosteroids. Allele frequencies for TNF1 and TNF2 were 81 and 19\%, respectively, and not different from those found in mild to moderate asthmatics (84\% and $16 \%$, respectively) or control subjects (table 5).

Based on skin prick tests, 68 asthmatics were found to be atopic, whereas 27 were considered as intrinsic. Intrinsic asthmatics were slightly older (mean \pm SEM age: $49 \pm 2.5$ yrs versus $38 \pm 1.5 \mathrm{yrs}, \mathrm{p}<0.01)$ and had lower serum $\mathrm{IgE}$ (geometric mean (range): $27 \mathrm{kU} \cdot \mathrm{L}^{-1}(<3.5-1660)$ versus 93 $\left.\mathrm{kU} \cdot \mathrm{L}^{-1}(<3.5-6230), \mathrm{p}<0.05\right)$ than their atopic counterparts. The two groups did not differ significantly from each other by their sex ratio, FEV1 values, or their tobacco consumption, but the proportion of patients reporting a childhood onset tended to be lower in intrinsic asthmatics than in atopic asthmatics (4 out of $27 ;(15 \%)$ versus 24 out of $68(35 \%) \mathrm{p}=0.08)$. In atopic asthma the TNF1 and TNF2 alleles frequencies reached 87 and $13 \%$, respectively, while corresponding figures in intrinsic asthma were 82 and $18 \%$ ( $>>0.05)$ (table 6). In asthmatics whose total serum IgE was beyond the normal range $\left(>114 \mathrm{kU} \cdot \mathrm{L}^{-1}, \mathrm{n}=34\right)$ the TNF2 frequency was $20 \%$ and not significantly different from the $15 \%$ found in asthmatics whose total serum IgE was within the normal range $(n=41)$.

Finally, 49\% (46/95) of asthmatics were current or exsmokers but those asthmatics with a smoking history displayed exactly the same frequencies for TNF1 and TNF2 alleles ( $84 \%$ and $16 \%$, respectively) as those who had never smoked. In addition smoking asthmatics did not differ significantly from smoking control subjects (table 7).

\section{Discussion}

In this study no significant association between adult asthma and a polymorphism located in TNF $\alpha$ gene promoter at position -308 was found and the authors were able to influence TNF $\alpha$ secretion in various experimental conditions [7-9]. In addition, the lack of association persisted irrespective of the asthma phenotypes.

The present study, which is the first to be conducted on European Caucasians, yields results which are at variance

Table 4. - Allele frequency for tumour necrosis factor (TNF) $\alpha-308$ polymorphism (alleles TNF1 and TNF2) in asthma according to the onset of the disease

\begin{tabular}{lrr}
\hline & \multicolumn{1}{c}{ TNF1 } & \multicolumn{1}{c}{ TNF2 } \\
\hline Control population $(\mathrm{n}=98)$ & $167 / 196(85)$ & $31 / 196(15)$ \\
Asthma onset $<15$ yrs $(\mathrm{n}=28)$ & $48 / 56(86)$ & $8 / 56(17)$ \\
Asthma onset $15-50$ yrs $(\mathrm{n}=47)$ & $77 / 94(82)$ & $17 / 94(18)$ \\
Asthma onset $>50$ yrs $(\mathrm{n}=20)$ & $34 / 40(35)$ & $6 / 40(15)$ \\
\hline
\end{tabular}

Data presented as frequency (\%). 
Table 5. - Allele frequency for tumour necrosis factor (TNF) $\alpha-308$ polymorphism (alleles TNF1 and TNF2) according to asthma severity

\begin{tabular}{lrr}
\hline & \multicolumn{1}{c}{ TNF1 } & \multicolumn{1}{c}{ TNF2 } \\
\hline $\begin{array}{l}\text { Control population }(\mathrm{n}=98) \\
\text { Asthma with FEV1 } \geq 60 \%\end{array}$ & $167 / 196(85)$ & $31 / 196(15)$ \\
$(\mathrm{n}=77)$ & $130 / 154(84)$ & $24 / 154(15)$ \\
$\begin{array}{l}\text { Asthma with FEV1 }<60 \% \\
(\mathrm{n}=18)\end{array}$ & $29 / 36(81)$ & $7 / 36(19)$ \\
\hline
\end{tabular}

Data presented as frequency (\%). FEV1: forced expiratory volume in one second.

with the previous studies assessing the association between the TNF $\alpha-308$ polymorphism and the prevalence of childhood asthma in Australia [10, 11]. Although discrepancies between the prescribed results and those of MOFFAT et al. [10] and AlbuQuerque et al. [11] might be explained by a different asthma phenotype (adult versus childhood asthma) these two studies yielded conflicting results. Indeed MOFFAT et al. [10] reported an increased prevalence of TNF2 allele in asthma while AlBuQUERQUe et al. [11] found the TNF1 allele to be more frequently associated with the disease. In the former study which included 92 asthmatics, the frequency of TNF2 reached $29 \%$ compared to $16 \%$ in the present study. It is of importance to note that the TNF2 frequency in the present control group $(15 \%)$ was very close to that found by MofFAT et al. [10] in their large cohort $(n=312)$ of nonasthmatic subjects $(17 \%)$. This suggests that the lack of association between adult asthma and TNF $\alpha-308$ polymorphism found is not due to a bias in the selection of control population. It could be argued that the asthmatics identified from a questionnaire sent to a general population as in the study of Moffat et al. [10] might be, on average, less severe than those seeking medical attention at the university hospital. However this hypothesis does not stand up to analysis of severe versus mild to moderate asthma.

Asthma is a broad term which encompasses several phenotypes. The candidate gene approach, in a polygenic disorder such as asthma, may be more appropriate to implicate some particular phenotypes, than to unravel a gene which would determine who is becoming asthmatic or not. Therefore, the present study aimed to characterize the asthmatics in terms of disease severity, atopy and smoking habit. In an attempt to see whether the TNF $\alpha$ polymorphism may modulate the disease severity, the asthmatic population were first subdivided into severe versus mild to moderate patients according to lung function. Among the functional indices, FEV1 was chosen because of its reproducibility and its use in the current Global Initiative for Asthma (GINA) guidelines [15].

Table 6. - Allele frequency for tumour necrosis factor (TNF) $\alpha-308$ polymorphism (alleles TNF1 and TNF2) in asthma according to the atopic status

\begin{tabular}{lrr}
\hline & \multicolumn{1}{c}{ TNF1 } & \multicolumn{1}{c}{ TNF2 } \\
\hline Control population $(\mathrm{n}=98)$ & $167 / 196(85)$ & $31 / 196(15)$ \\
Atopic asthma $(\mathrm{n}=68)$ & $112 / 136(82)$ & $24 / 136(18)$ \\
Intrinsic asthma $(\mathrm{n}=27)$ & $47 / 54(87)$ & $7 / 54(13)$ \\
\hline
\end{tabular}

Data presented as frequency (\%).
Table 7. - Allele frequency for tumour necrosis factor (TNF) $\alpha-308$ polymorphism (alleles TNF1 and TNF2) in asthma and control population according to the smoking habit

\begin{tabular}{lrr}
\hline & TNF1 & \multicolumn{1}{c}{ TNF2 } \\
\hline $\begin{array}{l}\text { Nonsmoking control population } \\
(\mathrm{n}=74)\end{array}$ & $125 / 148(85)$ & $23 / 148(15)$ \\
$\begin{array}{l}\text { Smoking control population } \\
(\mathrm{n}=24)\end{array}$ & $40 / 48(83)$ & $8 / 48(17)$ \\
$\begin{array}{l}\text { Nonsmoking asthma }(\mathrm{n}=48) \\
\text { Smoking asthma }(\mathrm{n}=46)\end{array}$ & $81 / 96(86)$ & $15 / 96(14)$ \\
\hline
\end{tabular}

Data presented as frequency (\%). Information about the smoking status was lacking in one asthmatic patient.

Asthmatics were considered to be severe if they displayed FEV1 values $<60 \%$ twice in the last 5 yrs, despite regular treatment with inhaled corticoids. The possibility of a particular association between TNF2 and severe asthma was examined for at least two reasons. The first is that such an association has been recently described for a subgroup of severe inflammatory bowel disease, the pathogenesis of which may somehow resemble that of asthma [16]. Secondly the inflammatory picture within the airways of severe asthmatics, involving both eosinophil and neutrophil (as opposed to the eosinophils alone in the mild to moderate forms of the disease) [1719] fits with a role for TNF $\alpha$ that favours the tissular recruitment of both type of granulocytes [20] partly through endothelial expression of ICAM-1 [21]. However, the present results fail to show any preferential association between TNF2 and severe asthma, even after excluding the smoking asthmatics. The lack of difference between mild to moderate and severe asthma found here is in agreement with a very recent study conducted in a large population from the USA, although in that study the authors reported a slight increase in the prevalence of genotypes 1-2 and 2-2 in 150 asthmatics, when compared to a random population (40 versus 30\%) [22]. Interestingly in the random population of that study, the prevalence of genotypes, including at least one TNF2 allele (genotype 1-1 and 1-2), is similar to the figure found in the present control population $(30 \%)$, which adds consistency in the interpretation of the data.

The present data do not demonstrate this TNF $\alpha$ polymorphism to be associated with atopy as defined by skin prick test to common aeroallergens nor with abnormally high total serum IgE levels, a phenotype which was previously shown to be linked to a mutation in the gene of FcReI [23]. Although the definition of atopy was restricted to skin prick test interpretation and not based on suggestive symptoms in the present study, it is believed that not many real atopic patients who could have been skin prick test negative for the two following reasons were missed. Firstly, because the mean age in our intrinsic asthmatics was 49 yrs, an age at which skin prick test are still regularly positive in atopic patients; secondly, because the intrinsic asthmatics had, on average, lower total serum IgE levels than atopic patients, clearly highlighting the real immunonological difference between the two groups.

Interestingly, almost one half of the patients diagnosed as having asthma on the basis of clinical symptoms and 
either bronchial hyperresponsiveness to methacholine or a significant reversibility of airway obstruction, were current or exsmokers. As no difference in the TNF $\alpha-308$ allelic frequencies have been found between smoking and nonsmoking asthmatics, the lack of association between asthma and this TNF-308 gene polymorphism in this study does not result from the fact that smokers were included in the population of asthmatics. Furthermore, the lack of difference between control smokers and asthmatic smokers suggests that TNF $\alpha-308$ polymorphism does not make smokers more prone to develop asthma. This observation can be compared with a very recent study by HigHAM et al. [24] showing that this polymorphism was not a risk factor for the susceptibility to chronic obstructive pulmonary disease in European Caucasian smokers.

In conclusion the data fail to show any significant association between asthma and the polymorphism at position -308 in the promoter of the TNF $\alpha$ gene, suggesting that this polymorphism is unlikely to play an important role in asthma pathophysiology. This conclusion holds for different phenotypes of asthma including the severe form of the disease.

\section{References}

1. Holgate ST. Asthma genetics: waiting to exhale. Nature Genet 1997; 15: 227-229.

2. Sandford A, Weir T, Pare P. The genetics of asthma. Am J Respir Crit Care Med 1996; 153: 1749-1765.

3. Los H, Koppelman GH, Postma DS. The importance of genetic influences in asthma. Eur Respir J 1999; 14: 1210-1227.

4. Holgate ST, Church MK, Howarth P, Morton EN, Frew AJ, Djukanovic R. Genetic and environmental influences on airway inflammation in asthma. Int Arch Allergy Immunol 1995; 107: 29-33.

5. Shah A, Church MK, Holgate ST. Tumor necrosis factor a: a potent mediator of asthma. Clin Exp Allergy 1995; 25: $1038-1044$.

6. Wilson AG, di Giovine FS, Blackmore AIF, Duff GW. Single base poymorphism in the human tumor necrosis factor alpha (TNF $\alpha)$ gene detectable by NcoI restriction PCR product. Hum Mol Genet 1992; 1: 353.

7. Wilson AG, Symons JA, McDowel TL, McDevitt HO, Duff GW. Effect of a polymorphism in the human tumor necrosis factor a promoter on transcriptional activation. Proc Natl Acad Sci 1997; 94: 3195-3199.

8. Bouma G, Crusius JBA, Oudkerk Pool M, et al. Secretion of tumor necrosis factor $\alpha$ and lymphotoxin $\alpha$ in relation to polymorphisms in the TNF genes and HLA-DR alleles. Relevance for inflammatory bowel disease. Scand $J$ Immunol 1996; 43: 456-463.

9. Louis E, Franchimont D, Piron A, et al. Tumor necrosis factor gene polymorphism influences tumor necrosis factor $\alpha$ production in LPS-stimulated whole blood cell culture in healthy humans. Clin Exp Immunol 1998; 113: 401-406.

10. Moffatt MF, Cookson WOCM. Tumor necrosis factor haplotypes and asthma. Hum Mol Genet 1997; 6: 551554.

11. Albuquerque RV, Hayden CM, Palmer LJ, et al. Association of polymorphisms within the tumor necrosis factor (TNF) genes and childhood asthma. Clin Exp Allergy 1998; 28: 578-584.

12. Louis R, Bury T, Corhay JL, Radermecker M. No increase in plasma histamine during PAF induced bronchoconstriction in allergic asthmatics. Chest 1993; 104: 806-810.

13. Bunce M, Taylor CJ, Welsh KI. Rapid HLA-DQB typing by eight PCR amplifications with sequence-specific primers (PCR-SSP). Hum Immunol 1993; 37: 201-206.

14. Verjans GM, Brinkman BMN, van Doornick CEM, Kijlstra A, Verweij CL. Polymorphism of tumour necrosis factor- $\alpha$ (TNF- $\alpha)$ at position -308 in relation to ankylosing spondylitis. Clin Exp Immunol 1994; 97: 45-47.

15. NHLBI/WHO Workshop Report. 1995. Global strategy for asthma management and prevention. National Institutes of Health. National Heart, Lung and Blood Institute, Bethesda, MD. Publication No. 95-3659.

16. Louis E, Peeters M, Franchimont D, et al. Tumour necrosis factor gene polymorphism in Crohn's disease: influence on disease behaviour? Clin Exp Immunol 2000; 119: 64-68.

17. Wenzel S, Szefler SJ, Leung D, Sloan S, Rex M, Martin R. Bronchoscopic evaluation of severe asthma. Persistent inflammation associated with high dose glucocorticosteroids. Am J Respir Crit Care Med 1997; 156: 737-743.

18. Jatakanon A, Uasuf C, Maziak W, Chung KF, Barnes PJ. Neutrophilic inflammation in severe persistent asthma. Am J Respir Crit Care Med 1999; 16: 1532-1539.

19. Louis R, Lau L, Broon A, Roldam B, Radermecker M, Djukanovic R. Relationship between airways inflammation and disease severity in asthma. Am J Respir Crit Care Med 2000; 161: 9-16.

20. Lukacs NW, Strieter RM, Chensue SW, Widmer M, Kunkel SL. TNF-alpha mediates recruitment of neutrophils and eosinophils during airway inflammation. $J$ Immunol 1995; 154: 5411-54517.

21. Pober JS, Grimbrone MA, Lapierre LA, et al. Overlapping patterns of activation of human endothelial cells by interleukin-1, tumor necrosis factor and immune interferon. J Immunol 1986; 137: 1893-1896.

22. Chagani T, Pare P, Zhu S, et al. Prevalence of tumor necrosis factor- $\alpha$ and angiotensin converting enzyme polymorphisms in mild/moderate and fatal/near fatal asthma. Am J Respir Crit Care Med 1999; 160: 278-282.

23. Shirakawa T, Li A, Dubowitz, et al. Association between atopy and variants of the $\beta$ subunit of the high affinity immunoglobulin E receptor. Nat Genet 1994; 7: 125-129.

24. Higham MA, Pride NB, Alikhan A, Morell NW. Tumour necrosis factor- $\alpha$ gene promoter polymorphism in chronic obstructive pulmonary disease. Eur Respir J 2000; 15: 281-284. 